\title{
THE NUCLEAR PATTERN OF THE NON-TECTAL PORTIONS OF THE MIDBRAIN AND ISTHMUS IN THE MINK
}

\author{
BUNLIANG TAMTHAI ${ }^{1}$ \\ Department of Anatomy, University of Michigan \\ RLEVEN PLATES (ELEVEN FIGURES) \\ INTRODUCTION
}

The material used in the preparation of this paper on the brain of the mink (Mustela vison) is a part of the Huber Neurological Collection and consists of the brain of the mink cut serially in transverse sections and stained by the Huber modification of the toluidin blue method. The descriptions of each nuclear group are supplemented by reference to the pertinent literature. Photomicrographs have been used for illustrations.

For the generous grant which made possible this research the writer wishes to express grateful acknowledgment to the Horace H. Rackham School of Graduate Studies of the University of Michigan. He also wishes to express his sincerest gratitude and indebtedness to Prof. Elizabeth Crosby. The author would also like to take this opportunity of expressing his thanks to Prof. C. Judson Herrick in appreciation of his suggestions and inspiring criticism during the course of the work.

THE PERIVENTRICULAR GROUPS

General areas of periventricular gray

Under this general heading the neuron masses immediately surrounding the cerebral aqueduct will be considered. According to their different locations, they may be placed in three subdivisions pars dorsalis, pars lateralis and pars ventralis (figs. 3 to 8 ). This

${ }^{1}$ A dissertation submitted in partial fulfillment of the requirements for the degree of doctor of philosophy. 
mesencephalic periventricular gray extends from a plane passing through the upper border of the pons to a level through the posterior commissure and the caudal part of the mammillary body. Rostrally, pars dorsalis appears caudal to the posterior commissure, and pars lateralis and pars ventralis replace the diencephalic-periventricular gray. Pars dorsalis forms the periventricular layers of the optic tectum. Caudally, pars dorsalis and the dorsal part of pars lateralis blend with the neurons of the nucleus of the inferior colliculus without sharp separation; the ventral part of pars lateralis and pars ventralis disappear at the level of the anterior medullary velum by fading into the central gray of the fourth ventricle. Rostrally, the medial portion of the dorsal nucleus of the posterior commissure differentiates from pars lateralis. In pars ventralis, the following nuclei have been observed: the eye-muscle nuclei including the oculomotor and the trochlear nuclei, the laterodorsal tegmental nucleus, the dorsal nucleus of the raphé, the dorsal tegmental nucleus and the nucleus of Darkschewitsch.

\section{Nuclear groups associated with posterior commissure}

The nucleus of the posterior commissure shows certain secondary subdivisions, the most outstanding of which are the magnocellular, the intracommissural and the central subcommissural portions. The nucleus of the posterior commissure is represented by two small, indistinct cell groups of irregular outlines. These two groups, the medial and the lateral, or central subcommissural portion or magnocellular part, are not clearly separated from each other. They occupy a position lateral to the deeper portion of pars lateralis of the periventricular gray (figs. 3 to 5) and extend from a plane through the rostral third of the chief oculomotor nucleus to the rostral part of the posterior commissure. At both poles they disappear gradually by fading into the surrounding subtectal gray. They correspond in general to the nucleus of the posterior commissure of Rioch ('29 a). The neurons constituting the medial group of this nucleus are small and multipolar with relatively large, indistinct nuclei, prominent nucleoli and very fine Nissl granules. They are mostly triangular in shape. In the more lateral portions these smaller cells are intermingled with larger neurons of a tegmental type - the presence of which has given the name pars magnocellularis to this portion.

Groups of cells intercalated among the fibers of the posterior commissure near pars dorsalis of the periventricular gray constitute an intracommissural portion of the nucleus of the commissure (figs. 4, 5). The cells of this nucleus are of the same type as the smaller cells in the pars magnocellularis with which the intracommissural portion is 
continuous laterally. This intracommissural portion is indistinet and inconstant and has a very short extent, blending with the subtectal gray surrounding it caudally and frontally. In its course it gradually approaches the midline as it is traced rostrocaudally, but the nuclei of the two sides do not meet each other at any level, as Brown ('43) found to be the case in the dog but not in the cat.

\section{Nucleus of Darkschewitsch}

The nuclear mass termed the nucleus of Darkschewitsch by Ramón y Cajal ('09-'11), and usually so designated in the literature, although it may not be the nucleus so described by the man whose name it bears, corresponds to nucleus accessorius medialis of Darkschewitsch by Zeri (1895). It appears at the level of the commissure and lies in pars ventralis of the periventricular gray but in a close relationship to the interstitial nucleus of the medial longitudinal fasciculus (figs. $2,3)$. At first it is located dorsomedial to the latter and then dorsal to it as traced caudorostrally. It is ventromedial to the nucleus of the posterior commissure and dorsolateral to the oculomotor nucleus. In spite of its close relationship to the interstitial nucleus of the medial longitudinal fasciculus, as a whole it can be differentiated from the latter, not only by its periventricular position, but also by its shorter length, smaller size and less conspicuous outline. The shape of the nucleus is somewhat round with irregular and indistinct boundaries. Rostrally and caudally, it fades into the periventricular gray without sharp demarcation.

This nucleus has been regarded by Perlia (1889), Tsuchida ('06) and Mingazzini ('28) as giving rise to oculomotor fibers. Such a distribution of its neuraxes has been denied by various observers (von Kölliker, 1896; Obersteiner, '01; Ramón y Cajal, '11; and others). The majority of workers have stated that a certain per cent of its neuraxes enter the posterior commissure, decussate there, and pass to the medial longitudinal fasciculus of the other side. Possibly the nucleus plays a rôle in the bilateral coordination of eye-muscle movements (Ariëns Kappers, Huber and Crosby, '36). This nuclear mass is composed of scattered, small to medium-sized, multipolar neurons with triangular and fusiform shapes.

\section{Eye-muscle nuclei}

Oculomotor complex. The oculomotor complex may best be considered by reference to the component parts of the cell group. The chief oculomotor nueleus corresponds to the gray mass which Le Gros Clark ('26) called the lateral oculomotor nucleus. It occupies a 
position directly dorsomedial and medial to the medial longitudinal fasciculus on either side of the midline (figs. 4, 5). It extends from a plane through the rostral end of the inferior colliculus to the level of the caudal part of the mammillary body. As it is traced caudorostrally, the number of cells gradually inereases and there is some tendency for the gray to fuse across the midline with its fellow of the opposite side (fig. 6). In about the rostral one-third of the nucleus, the cells begin to diminish and then finally disappear at the level of the caudal end of the mammillary body. The chief oculomotor nucleus can be more or less subdivided, though not sharply separated, into a dorsal or dorsolateral nucleus and a ventral or ventromedial nucleus (fig. 5). Dorsal or dorsolateral and ventral or ventromedial oculomotor nuclei are present in nearly all mammals. In the material available for study, the mink presents a longer ventromedial portion continuing throughout the entire extent of the chief oculomotor nucleus. This portion occupies a position medial to the medial longitudinal fasciculus on either side of the raphé (figs. 3 to 5 ). The ventromedial nuclei of the two sides approach each other at the midline and a median cell group, the forerunner of the central nucleus of Perlia, is formed in the midportions of the nucleus (fig. 6). The two nuclei are distinctly separated from each other, caudal and rostral to the level of the fusion. The median cell group corresponds to that which Le Gros Clark ('26) described as the paramedian nucleus.

The dorsolateral nucleus of the chief oculomotor complex is more or less circular in outline. It overlies the ventral nucleus and is dorsomedial to the medial longitudinal fasciculus (fig. 5). It is shorter than the ventral nucleus and commences slightly rostral to the caudal pole of the latter and terminates frontally by merging with it. In the mink, no further subdivisions are identifiable.

The cells of the chief oculomotor complex are large, multipolar neurons with large nuclei and distinet Nissl granules and nucleoli. They are typical efferent neurons. The central caudal nucleus, which Tsuchida ('06) and Le Gros Clark ('26) had described, was not found in the mink. In the material studied, the chief oculomotor nucleus is not directly continuous with the trochlear nucleus (fig. 7). There is quite a definite interval, extending over three sections, in which there are no neurons.

Close to the midline, in relation to the frontal end of the dorsomedial aspect of the chief oculomotor nuclei and extending rostral to the latter, is a group of small cells which has been called the EdingerWestphal nucleus. The nuclei of the two sides are fused into a single nuclear mass across the midline for the rostral half of the nuclei (fig. 4) but are different from each other in the caudal half (fig. 5). These neurons may be described as an unpaired nucleus with two 
caudally projecting extensions. This does not entirely agree with Panegrossi ('04) and Brouwer ('18) who stated that a paired EdingerWestphal nucleus is found only in the monkey and in man. It does agree, however, with Brown's ('43) account of the condition in the dog.

The cells of the Edinger-Westphal nucleus are multipolar and oval or triangular in outline. They are about half the size of the cells of the chief oculomotor complex. They have relatively large nuclei with fine Nissl granules. This nueleus is not well developed in the mink. It has a short extent. Directly in front of the Edinger-Westphal nucleus an elongated cell mass is observed. This is an unpaired structure, though it looke like the fusion of the nuclear gray of the two sides. This nuclear mass probably corresponds to what Panegrossi ('04) termed nucleus medianus anterior (fig. 2). Brouwer ('18) and Le Gros Clark ('26) described this nucleus as a part of the Edinger-Westphal nucleus (rostral Edinger-Westphal nucleus). In the mink, although it is found directly continuous with the latter, cells of the two groups can be differentiated from each other. Neurons of nucleus medianus anterior are smaller and more elongated. Most of them are of spindle or fusiform shape with relatively large nuclei. Their Nissl granules are obvious. As a whole, this nucleus has a greater length than does the Edinger-Westphal nucleus. It extends from the frontal end of the Edinger-Westphal nucleus to a plane through the caudal end of the mammillary body. In its course caudofrontally, the nucleus shifts ventralward from a position ventral to the central gray to a place midway between the cerebral aqueduct and the interpeduncular fossa (fig. 2). There is no agreement that this nucleus gives origin to root fibers. Frank ('21) supposed it to be concerned with the EdingerWestphal nucleus in forming a midbrain center for convergence.

Nucleus dorsocentralis posterior, an unpaired nuclear mass of Panegrossi (1898, quoted from Castaldi, '24), is not found in this material. Panegrossi described it as a very small nucleus lying between the caudal tip of nucleus medianus anterior and in front of the central nucleus of Perlia. The subfascicular nucleus of the oculomotor nerve of Frank ('21) is described as part of the annular nucleus of the medial longitudinal fasciculus in this paper (see below).

Trochlear gray. As seen in cross section material, the trochlear nucleus bears a close resemblance to the oculomotor gray. It occupies a position below the aqueduct at the level of the inferior colliculus, directly dorsolateral to the medial longitudinal fasciculus and partly embedded within this bundle (fig. 8). It is behind and slightly lateral to the plane of the chief oculomotor nucleus. In the horse, the trochlear gray is ventral to the medial longitudinal fasciculus (Tsuchida, '06 and Gillilan, ' $43 \mathrm{~b}$, fig. 22). Rostrally, there is a small gap between the frontal end of the trochlear gray and the caudal end of the oculo- 
motor complex. The shape of the nucleus is somewhat more nearly circular than that of the oculomotor gray and, on the whole, is smaller and of shorter extent.

The neurons constituting the trochlear nucleus are similar to those of the chief oculomotor complex. They are large and multipolar with distinct Nissl granules, being typical somatic efferent neurons. A small group of tiny cells lying in the ventral part of the periventricular gray, dorsal to the medial longitudinal fasciculus at the level of the trochlear decussation, was described by Westphal (1887), and confirmed by Obersteiner in the same year, as the Westphal or the posterior trochlear nucleus; it is probably a part of pars lateralis of the dorsal nucleus of the raphe in the mink.

Another gray mass, noted by Tsuchida ('06) and described by van Valkenberg ('12) as the posterior trochlear nucleus, if present, lies caudal to the principal trochlear nucleus. It has not been found in the material studied.

\section{Dorsal nucleus of raphé}

The dorsal nucleus of the raphe is one of the obvious elements of the ventral periventricular gray in the caudal half of the midbrain (figs. 7 to 8 ). It is composed of two parts - pars lateralis and pars centralis. Pars centralis is an elongated nuclear mass (figs. 7 to 8 ) situated in the midline throughout the caudal part of the midbrain and upper pontine levels. Its ventral half extends between the two medial longitudinal fasciculi; its dorsal half is bordered on either side by pars lateralis of the nuclear complex. The dorsal, intermediate and ventral parts of pars centralis, which have been described in some animals, could not be clearly differentiated in the material studied. Pars lateralis (figs. 7 to 8 ) is represented by circular cell masses bilaterally situated on either side of the central portion, dorsal and dorsolateral to the medial longitudinal fasciculus. Each mass has been called a supratrochlear nucleus (Stengel, '24).

Pars centralis extends from the upper pons region to about the level of the middle of the trochlear nucleus. Pars lateralis, however, is shorter in extent than pars centralis. It begins caudally in planes through the rostral end of substantia nigra and terminates frontally at a level through the caudal tip of the chief oculomotor complex. Both pars centralis and pars lateralis merge into the surrounding gray frontally and caudally without distinct lines of demarcation.

The neurons of the dorsal nucleus of the raphe are of the same type in both portions. They are large to medium-sized, multipolar triangular or spindle-shaped cells intensely stained in the toluidin 
blue preparations. They have relatively large nuclei with distinct nucleoli. Fine Nissl granules are distributed throughout their cytoplasm.

\section{Laterodorsal tegmental nucleus}

Directly dorsolateral to the dorsal tegmental nucleus at the caudal levels of the midbrain and in the aqueduct region, a group of neurons has been described as nucleus laterodorsalis tegmenti (Castaldi, '26). This group is in the lateral part of the central gray, ventromedial to the nucleus of the mesencephalic root of the trigeminal nerve (figs. 9, 10). It has an irregular outline with indistinct boundaries. Frontally, it ends at the level of the beginning of the cerebral aqueduct by merging into the periventricular gray. Caudally, it disappears about the same level as does the dorsal tegmental nucleus - that is, in the upper pons region - by fading into the central gray. At levels through the frontal end of nucleus medialis profundus its cells come into a very close relationship or even intermingle with the cells of the nucleus of locus coeruleus (fig. 10), which may be regarded as a special differentiation of the lateral part of nucleus laterodorsalis tegmenti.

The laterodorsal tegmental nucleus is composed of small and mediumsized neurons with various shapes from irregular and spindle to oval and triangular. Their nuclei and Nissl granules are indistinct. Castaldi ('26) discussed the possible relations of this nucleus to the trigeminal nerve and concluded that, although it might receive some fibers or possibly collaterals of the mesencephalic root of the trigeminal, it could not be considered a true and proper sensory nucleus of this nerve.

Nucleus of locus coeruleus has been considered in a number of contributions dealing with the nucleus of the mesencephalic root of $\mathrm{V}$. There still appears to be a difference of opinion in regard to both its cell types and its relations to this nerve. The human locus coeruleus has been described by Ranson ('40, and elsewhere) as a shallow groove, faint blue in color, extending from the superior fovea in the floor of the fourth ventricle to the cerebral aqueduct. Beneath locus coeruleus, he stated, are pigmented nerve cells composing substantia ferruginea. Locus coeruleus itself is sometimes called substantia ferruginea (Meynert, 1872; Forel, 1877). Willems ('11) used both terms, calling the cells internal to the mesencephalic root in the rabbit nucleus loci coerulei and those external to the root substantia ferruginea. By whatever name the cell mass is designated, there seems to be a considerable variance of opinion concerning the function and the types of cells constituting the nucleus of locus coeruleus.

In the material available for study, the nucleus of locus coeruleus appears as a rather well defined, compact group of cells (figs. 10, 
11). It lies directly lateral to the dorsal tegmental nucleus, ventral to the nucleus of the mesencephalic root of $\mathrm{V}$, medial to the root itself in its upper extent and medial to brachium conjunctivum in its lower extent. The nucleus begins rostrally at the level of the caudal end of nucleus medialis profundus in the isthmus and extends to the trigeminal levels of the pons. It is closely related with the nucleus of the mesencephalic root of $\mathrm{V}$ throughout its entire extent. It may be considered as representing a differentiated lateral pars of nucleus laterodorsalis tegmenti, with the main portion of which it is continuous rostrally. At certain levels the neurons of the nucleus of the mesencephalic root of $\mathrm{V}$ are intermingled with those of the nucleus of locus coeruleus (fig. 11). The neurons of the latter can be differentiated from those of the former, for they are much smaller, about half or one-third the size, and are not so deeply stained. These neurons of the nucleus of locus coeruleus are multipolar, medium-sized cells with various shapes: oval, triangular and elongated. They have relatively large nuclei with indistinct outlines. Coarse Nissl granules are irregularly distributed throughout their eytoplasm but rather concentrated near the periphery of the cell body. No pigment is found in these neurons. These observations seem to agree with those of Kuré (1899) and Weinberg ('28). Kuré described large and small cells in the nucleus of locus coeruleus of the rabbit. The large cells, he stated, were analogous to the cells in the nucleus of the mesencephalic root of $\mathrm{V}$ and underwent chromatolysis after cutting the trigeminal nerve, although the small cells were not affected. Weinberg also found two types of cells intermingled in the region, one of which was histologically different from those constituting the nucleus of the mesencephalic root of $\mathrm{V}$. He considered this type as forming the nucleus of locus coeruleus.

Many workers such as Meynert (1872), von Kölliker (1896), Johnston ('09) and Allen ('19) regarded the cells in locus coeruleus as a part of the mesencephalic nucleus of the trigeminal nerve. Willems ('11) considered the gray of locus coeruleus as a separate nucleus. Ramón y Cajal ('09) and Weinberg ('28) believed that no contribution to the mesencephalic root of the trigeminal nerve comes from the nucleus of locus coeruleus. May and Horsley ('10) and Kosaka ('12) failed to find any chromatolysis in the cells of locus coeruleus, the former after sectioning the trigeminal nerve in the monkey and cat, the latter after cutting the mandibular division of the trigeminal nerve in the dog. These differences in opinion about the functional relations of these neurons is dependent largely upon differences in the establishment of the limits of the nucleus of locus coeruleus (Weinberg, '28; Sheinin, '30). 
On the basis of their experimental study of the capillary bed of the nucleus of locus coeruleus in monkeys, Finley and Cobb ('40) concluded that this cell mass is distinct from the nucleus of the mesencephalic root of $\mathrm{V}$. They showed difference in capillary richness in the two nuclei and in the character of the constituent cells.

\section{Dorsal tegmental nucleus}

In the isthmus region, a distinct group of neurons is identified on either side of the midline within the central gray. It occupies a position ventromedial to the laterodorsal tegmental nucleus and directly ventral to the medial longitudinal fasciculus. This nuclear group is known as the dorsal tegmental nucleus (fig. 10) or nucleus tegmenti dorsalis of von Gudden, who described it, together with the ventral tegmental nucleus, in 1889.

In general, the nuclear mass is cireular in outline in cross section. In the middle third of its extent, it appears to consist of two distinct portions, a ventral and a dorsal part, with a few intervening scattered cells. The neurons of the two portions are almost the same except that those of pars dorsalis are slightly smaller and less numerous than those of pars ventralis. They are medium-sized, multipolar cells having various shapes from round or oval to triangular and fusiform. Frontally and caudally, the cells of the dorsal tegmental nucleus gradually fade into the surrounding periventricular gray without any sharp nuclear demaraction.

\section{Nucleus of mesancephalic root of $\boldsymbol{V}$}

This nucleus has been studied by a number of authors after the first clear differentiation of the mesencephalic root of $V$ from the trochlear nerve was given by Meynert (1872). Since the work of Johnston ('09), May and Horsley ('10), Willems ('11), Allen ('19) and Thelander ('24), it has been generally accepted that the mesencephalic nucleus of $\mathrm{V}$ contains primary sensory neurons, the processes of which course with the motor branches of the mandibular division of $\mathrm{V}$, supplying the muscles of mastication and mediating muscle sensibility. Central collaterals from the mesencephalic root were traced to the motor nucleus of $\mathrm{V}$ by Ramón y Cajal (1896) and this observation has been confirmed by Wallenberg ('04 c), May and Horsley ('10) and others. Further evidence of the sensory character of the mesencephalic nucleus as based on cell type is offered in the work of Sheinin ('30), who carefully studied the cells in the dog and separated them on the basis of size and arrangement of chromaphil substance into four types. However, Castaldi ('26), a more recent 
exponent of the view that the mesencephalic nucleus of $\mathrm{V}$ is motor and not sensory, based his objections to current opinions on his study of the embryologic development of the nucleus. He stated that this nucleus develops precociously as does the motor nucleus of the trigeminal and is larger in the embryo, at a stage at which the muscles are relatively retarded in development, than it is in the adult. Castaldi also noted that the long processes of its neurons show the characteristics of neuraxes of neurons of the central nervous system, particularly since they do not have Nissl substance and are myelinated, and that to regard these processes as dendrites would imply that the dendrites developed here before neuraxes, which is contrary to the usual course of embryologic development.

The autonomic function ascribed to the nucleus of the mesen. cephalic root of V by Lewy, Droff and Grant ('38) has not been corroborated by Corbin and Harrison ('41 and '42) and Corbin ('40). These latter authors, in their experiments on the cat, demonstrated action potentials of the proprioceptive type when the masticator muscles of the cat were stretched. Although they were unable to find fibers of the mesencephalic root of $\mathrm{V}$ in the oculomotor or trochlear nerves, they were not prepared to regard the presence of such fibers as impossible.

In the material studied, the nucleus of the mesencephalic root of $\mathrm{V}$ (figs. 5 to 11) appears in cross section either as a short, interrupted, vertically curved band formed by a few cells with the concave surface of the band turning inward, or, sometimes, just as a few conspicuous neurons. It is found caudally at the level of the motor nucleus of the $\nabla$ th nerve and extends rostrally to the level of the posterior commissure. The cells of the nucleus of the mesencephalic root of $V$ are scattered along the outer border of the periventricular gray (for variations in different forms, see Weinberg, '28), ventral, lateral and dorsal to the aqueduct, but most of them are lateral to it (figs. 5 to 11). They are bordered on the outside by stratum album profundum. No cells are found in sections passing through the midline or close to it. Very few cells are found at the frontal end of the nucleus, through the level of the posterior commissure, or throughout the upper third of its extent, but they gradually increase caudalward. The nucleus also shifts ventralward from a rostral position lateral to the aqueduct into closer contact with the nucleus of locus coeruleus at its caudal end (fig. 10). It is dorsal, dorsolateral and lateral to the latter and a few of its cells are intermingled with those of the nucleus of locus coeruleus (fig. 11). The number of cells varies at different levels. On the whole, cells of the mesencephalic root of the trigeminal nerve lie farther ventralward in most mammals than in lower vertebrates, and in man extend to the motor nuclei of the oculomotor and 
trochlear nerves, and are even intermingled with cells of these nuclei (Ariëns Kappers, Huber and Crosby, '36). Along its course, two major groups of neurons may be described, one at the level of the superior colliculus and the other in the isthmus. No definite group, but only scattered cells were seen in the material available at inferior collicular levels. Of the two groups; the caudal is the larger. The division of the nucleus of the mesencephalic root of $\mathrm{V}$ into lateral, medial and intermediate groups, such as is evident in many lower forms, is lacking in the mink. The augmentation of the caudal or isthmic portion of the nucleus has been noted for various mammals. It is evident in the cat and in rodents near the level of decussation of the trochlear nerve, in monkeys slightly in front of this level, and in man behind it (Weinberg, '28). In the guinea pig, Castaldi ('26) described an increase of cells at the level of the inferior colliculus, a decrease where the root passes downward and through the anterior medullary velum, and then an increase in planes through the motor nucleus of the trigeminal nerve. In the rodents studied by Weinberg ('28), the nucleus is not so well developed in the oculomotor region as in the cat, the monkey and man. Brown ('43) recognized three nuclear groups in dog and cat brains, the largest group being situated at superior collicular levels.

Cells of the mesencephalic root are rather uniform in outline. They are oval or pear-shaped. Two types of cells are identifiable - a large and a medium-sized neuron - although histologically they are almost alike. These neurons are mostly unipolar, but some of them are bipolar and a very few are multipolar. The two types of cells are scattered and intermingled with each other throughout the extent of the nucleus. They are not definitely located at any given level. In the mink, these neurons have definite outlines with distinct nucleoli. Fine and coarse Nissl granules are distributed throughout their cytoplasm. The large cells probably correspond to type A, and the smaller to types B and C of Sheinin ('30).

\section{MIDTEGMENTAL NUCLEAR GROUPS}

Nuclear groups associated with medial longitudinal fasciculus

Two cellular masses have been described in association with the medial longitudinal fasciculus. These are the interstitial nucleus of the fasciculus and the annular nucleus.

The cell group corresponding to the interstitial nucleus has been described under various names such as the interstitial nucleus of Ramón y Cajal ('11), nucleus commissurae posterioris of von Kölliker (1896), upper oculomotor nucleus of Darkschewitsch (1889) and nucleus of Darkschewitsch of Zeri (1895). The last name is often con- 
fused with the nucleus of Darkschewitsch as designated by Ramón y Cajal which is described in this paper under the name used by this author and by Ingram and Ranson ('35).

The interstitial nucleus of the medial longitudinal fasciculus is present, at the level of the rostral pole of the oculomotor nucleus, as a small circular cell group ventrolateral to the ventral nucleus of the posterior commissure, dorsolateral to the oculomotor nuclear complex and directly dorsal and dorsolateral to the medial longitudinal fasciculus (figs. 2, 3). In its course caudorostrally, it becomes more and more distinet, but rather abruptly disappears frontally at the level of the rostral tip of the nucleus medianus anterior (or rostral Edinger-Westphal nucleus). The cells of the interstitial nucleus of the medial longitudinal fasciculus are not closely packed together. They are relatively large and multipolar with oval and polygonal shapes. They have large nuclei with distinct nucleoli and coarse Nissl granules. This nucleus is a derivative, in part at least, of nucleus reticularis superior mesencephali of lower forms.

Another nuclear group associated with the medial longitudinal fasciculus is the annular nucleus. It lies on either side of the midline, ventral to the medial longitudinal fasciculus and the nucleus of the oculomotor nerve, and dorsal to the decussation of the brachium conjunctivum or superior cerebellar peduncle (figs. 7, 8). It begins caudally at the level of the frontal half of the trochlear gray and ends rostrally at a plane through the caudal tip of the red nucleus. It has a half-ring shape with an irregular and indistinct outline. The concave surface turns dorsalward embracing the medial longitudinal fasciculus.

The nucleus appears to occupy a position comparable in part to that of cells described by Castaldi ('23) as nucleo anulare del fascio longitudinale mediale and also to the subfascicular nucleus of the oculomotor complex of Frank ('21). The nuclear mass is composed of irregularly scattered, small to medium-sized multipolar neurons with elongated and fusiform shapes. Their nuclei and Nissl granules are indistinct. Toward the midline, the neurons of the nucleus blend with the cells of the raphé.

\section{Red nucleus}

The red nucleus appears as a conspicuous oval group of cells in the tegmental region of the midbrain. It extends from a plane through the caudal end of the superior colliculus to the subthalamic region, disappearing at levels through the caudal end of the mammillary body and the posterior commissure by blending indistinctly with the reticular formation. The red nucleus occupies a position ventrolateral 
to the oculomotor nuclei, the medial longitudinal fasciculus and the dorsal tegmental decussation. Substantia nigra is ventrolateral to it.

The fibrous capsule of the carnivore red nucleus is formed by the decussated fibers of the superior cerebellar peduncle, according to von Monakow ('10) and Rioch ('29 b). In the toluidin blue preparations this relation is not clear. The absence of such a capsule in the dog was noted by Hatschek ('07).

The red nucleus has been subdivided in many ways and it is uncertain to what extent the subdivisions are directly comparable in the different mammals (Foix and Nicolesco, '25, quoted from Ariëns Kappers, Huber and Crosby, '36). However, in the material studied, three subdivisions of the nucleus have been observed, each of which will be deseribed separately.

The magnocellular red nucleus (figs. 2 to 5) has the greatest length of any of the three parts and is present throughout the entire extent of the complex. It is most conspicuously seen at the caudal pole and gradually diminishes in size as it is traced rostrally. At the caudal end of the nucleus, it is ventrolateral to the parvocellular portion but, as it is followed rostrally, it shifts medialward so that it becomes first ventral (fig. 5) and then ventromedial to the parvocellular part (fig. 2). Its cells are large, multipolar and pyramidal neurons of the type recognized as efferent in character.

In the material studied, the parvocellular portion occurs for about the middle two-fifths of the entire extent of the red nucleus. A less frontal extent has also been found in the rabbit (Davenport and Ranson, '30). Its cells are small, multipolar and triangular or spindleshaped and are less closely packed than in the magnocellular portion.

The medial part of the red nucleus, at about the middle of its extent or at the level of emergence of root fibers of the oculomotor nerve, is penetrated through both magnocellular and parvocellular portions by the fibers of that nerve, separating a few scattered cells from the main nucleus. This secondary subdivision has formed adventitious groups (Davenport and Ranson, '30). In the material available, only a few scattered cells of this type have been observed (fig. 5).

A small, round mass of tiny cells, corresponding to the group which von Monakow ('10) called nucleus minimus, is found lateral to the magnocellular portion at the level of the midregion of the red nucleus (figs. 3 to 5 ). Its neurons are smaller than those of the parvocellular portion. They are multipolar, polygonal and, in some instances, triangular in shape, with large nuclei and prominent nucleoli. They have distinct Nissl granules. The cell group was also described by Davenport and Ranson ('30). Many others (Forel, 1877, in the dog; Hatschek, '07, in carnivores and primates; Ramón 
y Cajal, '09-'11, in the cat; and also Rioch, '29 b, in the cat) have described the red nucleus in carnivores without mentioning nucleus minimus.

\section{Deep mesencephalic gray (nucleus mesencephalicus profundus)}

Nucleus profundus mesencephali, the deep mesencephalic or tegmental gray, consists of multipolar, medium-sized, triangular-shaped and small-sized fusiform neurons scattered in the area ventral to the central gray, dorsal to substantia nigra and lateral to the midline. (fig. 5). This mesencephalic gray is found throughout the midbrain region, extending from the upper pons level caudally to the caudal end of the diencephalon frontally. On account of its general reticular character, Castaldi ('23) regarded it as the direct continuation forward of nucleus reticularis of the pons. Deep mesencephalic gray is seen best at the levels of the red nucleus; there two well organized groups of reticular cells are observed. One of these is located dorsal to the red nucleus, pars dorsalis of nucleus mesencephalicus profundus, and the other is lateral to the same nucleus, pars lateralis of nucleus mesencephalicus profundus. The dorsal group is more distinct than the lateral group and its neurons are larger than those of the latter. Cells of both dorsal and lateral groups are not closely arranged. Deep mesencephalic gray or nucleus mesencephalic profundus has received a number of names (see Castaldi's paper, '23, p. 144). One of the most common names is that of nucleus lateralis mesencephali of Marburg ('03).

\section{Ventral tegmental area and nucleus of mammillary peduncle}

Small clusters of cells appear in the ventral part of the mesencephalon lateral to the interpeduncular nucleus throughout the entire extent of the midbrain (figs. 3 to 5 ). This is the ventral tegmental area of Tsai ('25). Caudally, it seems to continue from the rostral tip of the scattered pontine gray without specific boundary. Frontally, this ventral tegmental gray blends with the gray of the hypothalamus.

In this ventral tegmental gray, a small, rather oval group of more closely arranged cells may be observed. This small group of cells has been designated the nucleus of the mammillary peduncle (figs. 4 and 5; see also Papez, '23, '32, and Fox, '41). It occupies a position lateral and dorsolateral to the interpeduncular nucleus, ventrolateral to the interstitial nucleus of the commissure of Forel, directly medial to the nucleus of the basal optic root and ventromedial to the red nucleus. It lies in relation with fibers of the mammillary peduncle. 
The ventral tegmental gray corresponds to nueleus ventralis tegmenti of Tsai ('25, fig. 4), and Rioch ('29 b, fig. 2). It is not the same as nucleus ventralis tegmenti of von Gudden and Ramón y Cajal ('09-'11). The latter nucleus is described in this paper under the name of nucleus medialis profundus.

At the level of emergence of the oculomotor fibers, the ventral tegmental area and its differentiated portion, the nucleus of the mammillary peduncle, are traversed by some of the most medial fibers of that nerve (figs. 4, 5). The ventral tegmental gray has very indefinite boundaries and in some sections it is difficult to differentiate it from the medial part of substantia nigra. Kosaka and Hiraiwa ('15) and Castaldi ('23) considered it as a part of substantia nigra. In the material available for study, the neurons of both the ventral tegmental area and the nucleus of the mammillary peduncle are much the same. They vary in size from small to large neurons and in shape from oval, fusiform or polygonal to triangular. Most of the large cells are triangular and much like the constituent elements of substantia nigra. They have large nuclei, coarse Nissl granules and prominent nucleoli. These large neurons are intermingled with small and medium-sized cells.

\section{Nucleus medialis profundus}

A group of neurons in the tegmentum of the isthmus, behind the mesencephalon, situated on either side of the raphé, ventrolateral to the medial longitudinal fasciculus and the dorsal tegmental nucleus and at the level of decussation of the trochlear fibers is termed nucleus medialis profundus (Castaldi, '23). The gray mass has a number of other names (see list in Castaldi, '23), one of the most common of which is nucleus ventralis tegmenti of von Gudden (1889) and Ramón y Cajal ('09-'11). The cell group is circular in outline, with indistinct boundaries (fig. 9). Caudally and frontally, it disappears by fading indistinctly into the surrounding gray. This nucleus is most conspicuous throughout the middle of its extent, the rostral tip being slightly more ventral than the rest of the nucleus.

The neurons constituting nucleus medialis profundus are deeply stained in the toluidin blue preparations and thus the cell mass stands out distinctly from the surrounding gray. The cells are medium-sized and multipolar and have irregularly oval to triangular or spindle shapes. Their nuclei are fairly large with indistinct outlines. Nissl granules were not clearly observed. Comparative studies show that this nucleus is better developed in lower than in higher mammals (Hatschek, '03). A fibrous capsule such as that described by Hatschek is not identifiable in the material studied. 


\section{Marginal nucleus of superior cerebellar peduncle}

At the level of the inferior collicular nucleus, clusters of small muitipolar cells are seen scattered among the fascicles and on both sides of the superior cerebellar peduncle, as its courses rostromedioventrally toward its decussation. This group of cells is the so-called marginal nucleus of the peduncle (fig. 10), and is present throughout the inferior collicular level. It approaches pars lateralis of nucleus mesencephalicus profundus.

\section{Cuneiform area}

The cuneiform area (figs. 9, 10) lies between the periventricular gray on its dorsomedial side and the inferior colliculus on its dorsolateral side, and occurs throughout the extent of the inferior collicular nucleus. This area consists of two types of scattered cells: small, fusiform or oval, multipolar neurons which tend to be surrounded by medium-sized, multipolar, triangular-shaped cells. Some fibers from the optic tectum and also some of the lemniscal system pass through this area, though they are not clearly seen in the available. material.

\section{Certain pretectal and subtectal components of tegmentum}

Pretectal nucleus. In the cross sections of the rostral portions of the mesencephalon, at the level of the posterior commissure, medial to the large-celled nucleus of the optic tract, dorsal to the dorsal nucleus of the posterior commissure and slightly dorsolateral to pars dorsalis of the periventricular gray and the posterior commissure lies a group of neurons which is designated as nucleus pretectalis (fig. 2). This gray corresponds to the pretectal nucleus of Tsai in the opossum ('25) and of Ingram, Hannett and Ranson in the cat ('32) and, in general, to the pretectal area of Gurdjian in the rat ('27).

The pretectal nucleus of the present account appears in the available transverse series as a small group of neurons rather circular in outline but with very indistinct boundaries (fig. 2). Frontally, it is continuous with the caudal portion of the diencephalon and caudally it disappears at the level of the posterior commissure by fading into the surrounding tectal gray (stratum griseum intermediale) without sharp demarcation. The neurons of this nuclear mass are small, multipolar and lightly stained. Most of them are triangular in outline, but some are fusiform and irregular in shape with very fine Nissl granules.

Nuclear gray associated with lateral lemniscus. Along the course of the lateral lemniscus, three nuclear groups - an upper or dorsal, 
a caudal ventral, and a rostral ventral nucleus of the lateral lemniscus - may be recognized.

The upper or dorsal nucleus of the lateral lemniscus appears in the cross section series as a rather elongated group of neurons dorsally located among the fibers of the lateral lemniscus. It is ventral to the inferior colliculus, lateral to nucleus medialis profundus and dorsal to the caudal ventral nucleus of the lateral lemniscus (figs. 9, 10). It extends from the level of the caudal end of the nucleus medialis profundus to about that of the rostral tip of the same nucleus. In many mammals, according to Ariëns Kappers, Huber and Crosby ('36) and others, this nucleus, which is situated in front of the level of entrance of the trigeminal nerve in the lateral part of the field close to the lateral lemniscus, from its position, as well as from the general character of its cells, its fiber connections and relations with the inferior colliculus, suggests part at least of the nucleus isthmi of reptiles. The dorsal nucleus of the lateral lemniscus corresponds to the parabigeminal body of Papez ('29). This nucleus, as it is traced rostrocaudally, gradually becomes smaller toward the caudal end. Its neurons are closely packed, medium-sized, multipolar cells and are triangular or fusiform in outline. Their nuclei are relatively large. Fine Nissl granules are distributed throughout their cytoplasm. In the cross sections studied, the neurons of this nucleus are grouped peculiarly, in linear arrangement although the cellular lines are somewhat irregular (fig. 9).

At about the same level or slightly caudalward to the dorsal nucleus of this fiber system, and also along the course of the lateral lemniscus, is a group of cells ventrally placed which is described as the caudal ventral or lower nucleus of the lateral lemniscus (figs. 9, 10). It is connected with the dorsal nucleus by clusters of scattered cells. The caudal ventral nucleus is rather oval or elongated in'shape with irregular, indistinct boundaries. It becomes larger and more conspicuous toward its caudal end. It extends farther caudalward than does the dorsal nucleus. Its cells are smaller than those of the latter cell mass, and are also small multipolar neurons, oval and triangular in shape with relatively large nuclei and very fine Nissl granules. This caudal ventral nucleus, especially in its dorsal portion, presents a linear arrangement of its constituent cells similar to that seen in the dorsal nucleus of the lateral lemniscus.

The rostral ventral nucleus of the lateral lemniscus, the smallest nucleus of the three cell masses associated with the lateral lemniseus, is the most rostral and has the shortest extent (fig. 8). It appears caudally at the level of the caudal tip of the trochlear nucleus and extends rostrally, toward the medial geniculate body, to the level 
of the frontal end of the same nucleus. It lies also along the course of the lateral lemniscus. The rostral ventral nucleus is in line with the dorsal nucleus of the lateral lemniscus, but nearer to the lateral surface of the midbrain. This group of cells is fusiform in outline, and is best developed through the middle of its extent. The neurons constituting it are mostly small multipolar cells, triangular in outline. A few of them are medium-sized multipolar cells. They are lightly stained in the available Nissl material and have relatively large nuclei and coarse Nissl granules.

\section{MIDLINE NUCLEAR GROUPS}

\section{Linear nuclear gray}

The linear nuclear gray is an unpaired cell mass which appears in cross section as an elongated column ventral to the central gray. It extends throughout the midbrain from the pontine raphé caudally to the caudal end of the diencephalon frontally. Three subdivisions can be recognized - the caudal, the intermediate and the rostral linear nuclei.

The caudal linear nucleus is located at the midline between the medial longitudinal fasciculi and the nuclei mediales profundi of the two sides (figs. 9, 10). It extends forward from the gray of the pontine raphé to the decussation of the superior cerebellar peduncle. A few scattered cells of the same type form an interstitial nucleus for that decussation. There is a cellular connection between the dorsal part of the linear nuclear gray and the ventral part of pars centralis of the dorsal nucleus of the raphé, so that pars centralis and the caudal linear nuclear gray appear, in the cross section, as a single elongated cell column extending from the cerebral aqueduct dorsally to the pontine raphé ventrally (fig. 9). This column is distinct from the surrounding gray because of its deeply stained neurons. The caudal linear nuclear gray is composed of intensely stained, irregularly scattered neurons. They are small to medium-sized, spindle- and fusiform-shaped neurons with indistinct nuclei and Nissl granules.

The intermediate portion of the linear nucleus is not so distinct as the caudal part, consisting of cells which are few in number and not closely arranged. It extends from the rostral pole of the decussation of the superior cerebellar peduncle caudally to the commissure of Forel frontally, lying between the red nuclei of the two sides. At the level of the interpeduncular nucleus, there is a small group of rather large, multipolar, deeply stained neurons between the ventral part of the intermediate linear nuclear gray and the dorsal part of the interpeduncular nucleus, similar to those of the caudal linear gray except that they are less intensely stained. 
The rostral linear nucleus is continuous with the intermediate linear gray. It extends from a level in front of the commissure of Forel to the caudal pole of the diencephalon, in the same relation to the red nucleus as is the intermediate linear gray. The cells are few in number, widely scattered and of the same type as those of the intermediate linear gray.

\section{Interstitial nucleus of commissure of Forel}

The interstitial nucleus of the commissure of Forel (figs. 2 to 4) appears as an unpaired midline group of scattered neurons intercalated among the commissural fibers. Caudally, it seems to be directly continuous with the dorsal part of the rostral portion of the interpeduncular nucleus. Rostrally, the interstitial nucleus appears to blend with the mammillary nueleus and the surrounding hypothalamic gray without definite line of demarcation. It is most obvious in the middle half of its extent. The group of cells is rather oval in outline with indistinct and irregular boundaries. It lies between the ventral tegmental area and the nucleus of the mammillary peduncle of one side and corresponding areas on the other side (figs. 2 to 4 ). In its lower portion, oculomotor root fibers form its lateral boundaries. Some of the most medial of these fibers traverse the nucleus in certain sections (fig. 4). As the interstitial nucleus of the commissure of Forel is traced caudorostrally, at about the middle third of its extent, the dorsal part of the nucleus appears to spread out laterally into two wings (fig. 3). The dorsal part of each wing extends toward the magnocellular part of the red nucleus and blends with the latter. The ventral part spreads toward the ventral tegmental gray, the nucleus of the mammillary peduncle and the medial part of substantia nigra. The interstitial nucleus of the commissure of Forel corresponds to the interstitial nucleus of the supramammillary decussation figured by Rioch ('29 a, figs. 9 to 11).

The interstitial nucleus is constituted of various sized neurons. At least two types can be identified in the material studied. One of these is a large, multipolar cell with an oval, elongated or triangular cell body. It has a cell nucleus and a large, distinct nucleolus and the processes are unusually prominent in the available material. The coarse and distinct Nissl granules are distributed throughout the cell cytoplasm. Neurons of this type are not very numerous and are seen more usually in the two wings of the nucleus. A second, more widely distributed type, has an oval or round cell body, much smaller than that of the first type and less clearly delimitable. The outlines of the cell nucleus and nucleolus are difficult to trace, and the Nissl granules are very fine indistinct and less in number than in the other type of 
neuron. The processes are short, less numerous and less easily followed than those of the first type. These smaller cells are distinguished throughout the nucleus, intermingled with the larger neurons.

\section{Interpeduncular nucleus}

The interpeduncular nucleus is a conspicuous element of the midventral region of the mesencephalon and is easily recognizable. It is located between the two cerebral peduncles in the field overlying the interpeduncular fossa (figs. 3 to 6 ). It is found continuously from the upper pontine gray caudally to the caudal end of the mammillary body rostrally, fading out into the ventral tegmental gray without a definite line of demarcation. At the level of emergence of the fibers of the oculomotor nerve, the interpeduncular nucleus is penetrated by some of those fibers (fig. 5). This gray mass is an unpaired structure throughout its entire course.

Two types of cells are found in the interpeduncular nucleus. One is a medium-sized, fusiform or triangular multipolar neuron with a large nucleus. Its Nissl granules are not very distinct. The cells of this type are intermingled with small, round or oval more deeply stained neurons, having tiny but distinct cell nuclei. In the superficial part of the nucleus, the larger cells are more numerous than the smaller type, but in the central portion they are surpassed in number by the smaller neurons. Cells at the center of the interpeduncular nucleus are more closely arranged than those of the superficial zone. There is no definite line of demarcation between the two zones such as was described in the rabbit by Ramón y Cajal ('09-'11). Early, Forel (1877) recognized the presence of these small and large cells in the interpeduncular nucleus in the rabbit.

\section{BASAL MIDRRAIN GRAY}

\section{Substantia nigra}

In transverse sections, substantia nigra appears as two irregular, thick cell bands overriding and in part intermingled with the fiber bundles of the cerebral peduncle (figs. 2 to 8 ). It begins caudalward at the level of the upper border of the pons, replacing pontine gray, and continues uninterruptedly through the length of the midbrain into the subthalamic region of the diencephalon, where it gradually disappears. Its forward projection into the ventral part of the carnivore diencephalon was also described in the eat by Winkler and Potter ('14).

Substantia nigra is not equally thick throughout. Caudally, towards the lateral sulcus, it becomes thin, although it has considerable thick- 
ness near the medial side of the cerebral peduncle. Farther forward these relations are reversed, the lateral part being the better developed portion. The medial part of substantia nigra is traversed by the emerging rootlets of the oculomotor nerve (fig. 5). The surface turned towards the tegmentum is slightly concave in the caudal part, straight in the middle portion and slightly convex rostralward. In the material available for study, substantia nigra may be divided into the three parts which Rioch ('29 a) and others have described in carnivores.

Zona compacta is the most conspicuous of any of the three portions of substantia nigra and is found throughout the entire extent of the nuclear mass (figs. 2 to 8 ). Its cells are elosely arranged, and are small or medium-sized and mostly polygonal or fusiform in shape. They have large nuclei and distinct Nissl granules. This portion of substantia nigra overrides the cerebral peduncle throughout its extent.

Zona reticulata, which is merely a prolongation of cells of zona compacta, appears as scattered neurons intercalated among the fibers of the cerebral peduncle (figs. 3 to 5 ). There is no definite fibrous layer between this zone and zona compacta. This portion of substantia nigra extends from a plane passing through the rostral end of the decussation of the superior cerebellar peduncle to a level through the caudal end of the mammillary body. Its cells are much the same as those of zona compacta. Ramón y Cajal ('09-'11) described this part as an inferior zone of substantia nigra.

Pars lateralis is found dorsolateral to zone compacta and ventromedial to the medial geniculate body (fig. 5). It has about the same extent as does zona reticulata. The neurons constituting this part of substantia nigra are fusiform and slightly smaller than those of zone compacta. Histologically, they are much like those of the other two portions of the nuclear complex.

\section{Nucleus of basal optic root}

The nucleus of the basal optic root with its connections in various mammals has been studied recently in detail by Gillilan ('41). In the mink, it is an oval cell mass with indistinct and irregular boundaries, which occupies a position along the inner border of substantia nigra (figs. 3 to 5). It has so close a relationship to this latter gray that, in some sections, it is rather difficult to differentiate clearly between them. The constituent elements are also similar to those of substantia nigra in the shrew, the bat, and the cat, and probably generally in mammals.

In the mink, the nucleus of the basal optic root begins caudally at the level of the caudal pole of the interpeduncular nucleus or the caudal part of the red nucleus. It disappears frontally at the caudal 
end of the mammillary body. In the middle third of its extent, the nucleus appears, in cross sections, to consist of two portions - a lateral or dorsolateral and a medial or ventromedial subdivision indistinctly separated from each other (fig. 3). Wallenberg ('04) also found two portions of this nucleus in the guinea pig. He termed the dorsolateral group of cells "ganglion ectomammillare dorsalis" and the ventral group "ganglion ectomammillare ventralis." A small band of cells connects the two nuclear masses. The form and position of the ventral nuclear mass are, as Wallenberg stated, similar to those of the avian ganglion ectomammillare (Huber and Crosby, '29). This was the embryonic position of nucleus tractus optici basalis and as the main group of cells was shifted to its dorsolateral position with the downgrowth of the peduncular fibers, a small number of the cells retained the original relationship. Kosaka and Hiraiwa ('15) described this separation of the nuclear elements in the dog also.

In its upper portion, the nucleus of the basal optic root is traversed by oculomotor nerve fibers (fig. 5). The neurons of this nuclear mass are mostly small and medium-sized, are multipolar but with various shapes - irregular, elongated and triangular. They have relatively large nuclei but rather indistinct cell outlines. The nucleoli are not very distinct. The cells are smaller than those of substantia nigra.

\section{SUMMARY}

Among the periventricular group, the eye-muscle nuclei probably present the most interesting relations. A forerunner of the central nucleus of Perlia or paramedian nucleus occurs in midregions of the chief oculomotor gray. Caudal and rostral to this level, the chief oculomotor gray is distinetly bilateral. No central caudal nucleus was identified. The EdingerWestphal nuclei of the two sides are fused rostrally, but separate caudally. Trochlear nuclei are distinctly separated from the oculomotor gray. No posterior trochlear nucleus has been identified on either side of the brain.

Two portions were recognized in the dorsal tegmental nucleus - the dorsal and ventral parts. In this respect, the nucleus differs from that of any other mammals considered in the present series of papers.

A nucleus of locus coeruleus, probably differentiated from the lateral part of the laterodorsal tegmental nucleus of lower forms, has been recognized in the mink. It is clearly definable 
from the nucleus of the mesencephalic root of $\mathrm{V}$ on the basis of cell differences, although the neurons of the two nuclear masses are somewhat intermingled. Only two major cell groups of the nucleus of the mesencephalic root of $\mathrm{V}$, one at superior collicular levels and the other in the isthmus, have been identified in the mink.

Among the midtegmental nuclear groups, the red nucleus is probably the most interesting. In addition to a parvocellular and a large magnocellular portion, a nucleus minimus, such as that described by von Monakow (1895), has been recognized. The fibrous capsule, described by von Monakow ('10) and Rioch ('29 b) as characteristic of carnivore red nucleus, is not clearly differentiable in the mink series studied for this paper.

Of the linear complex, the caudal linear group is the best developed in the mink. The interstitial nucleus of the commissure of Forel, consisting of scattered neurons among the fascicles of this system, has the characteristic relations to the red nucleus, substantia nigra, the nucleus of the basal optic root and the mammillary body, as it spreads laterally from the midline along the course of its associated fibers. The interpeduncular nucleus is a conspicuous grav mass in the ventral midline region of this carnivore, being found throughout the extent of this brain block.

Substantia nigra has the three portions and the relations described for carnivores by Rioch ('29 b) and others. The nucleus of the basal optic root lies in intimate relations with it, resembling it closely in general appearance. 
PLATE 1
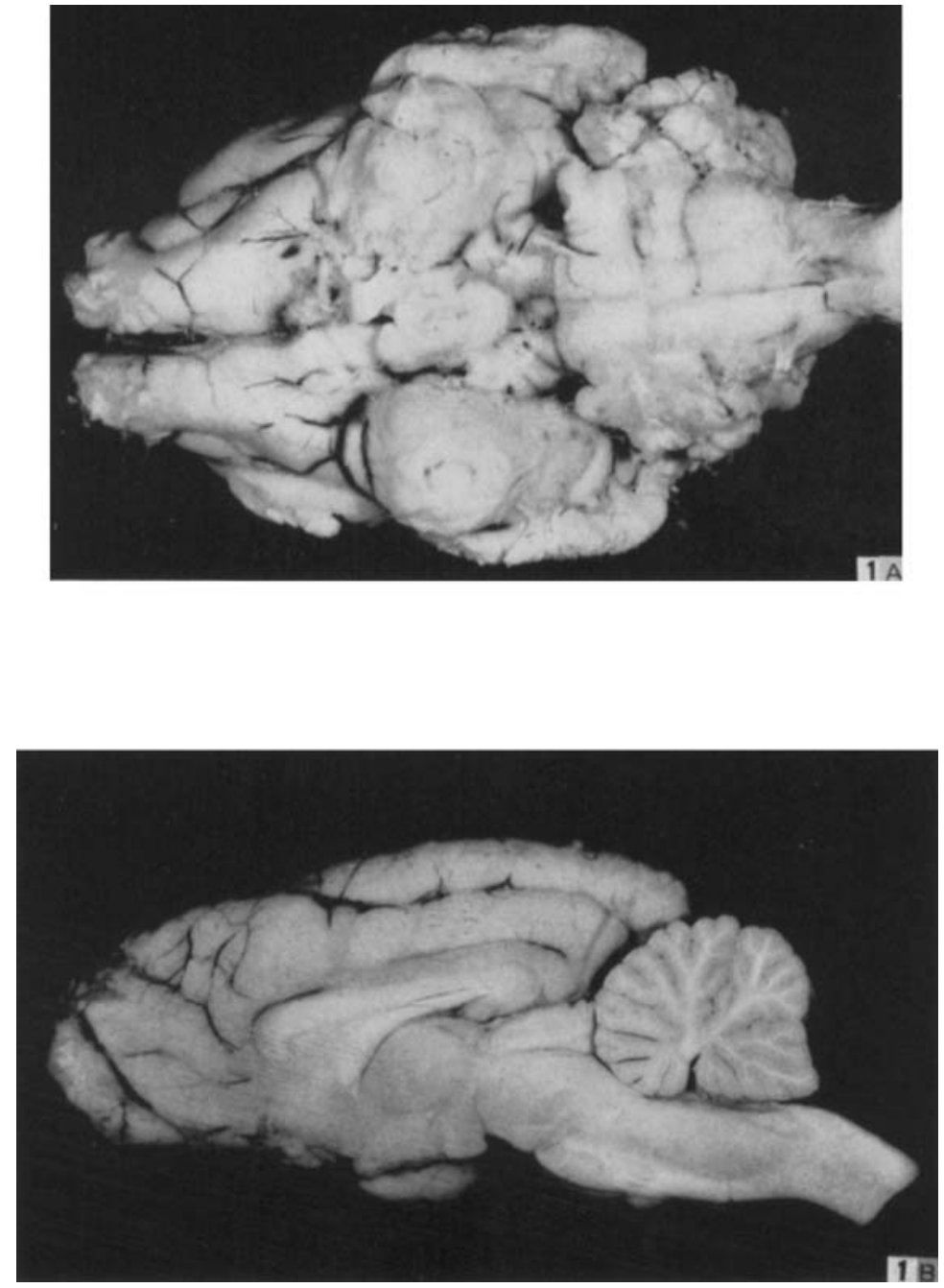

1a Photograph of the ventral aspect of the mink brain. $\times 2$.

1b Photograph of the mink brain as seen in midsagittal section. $\times 2$. 


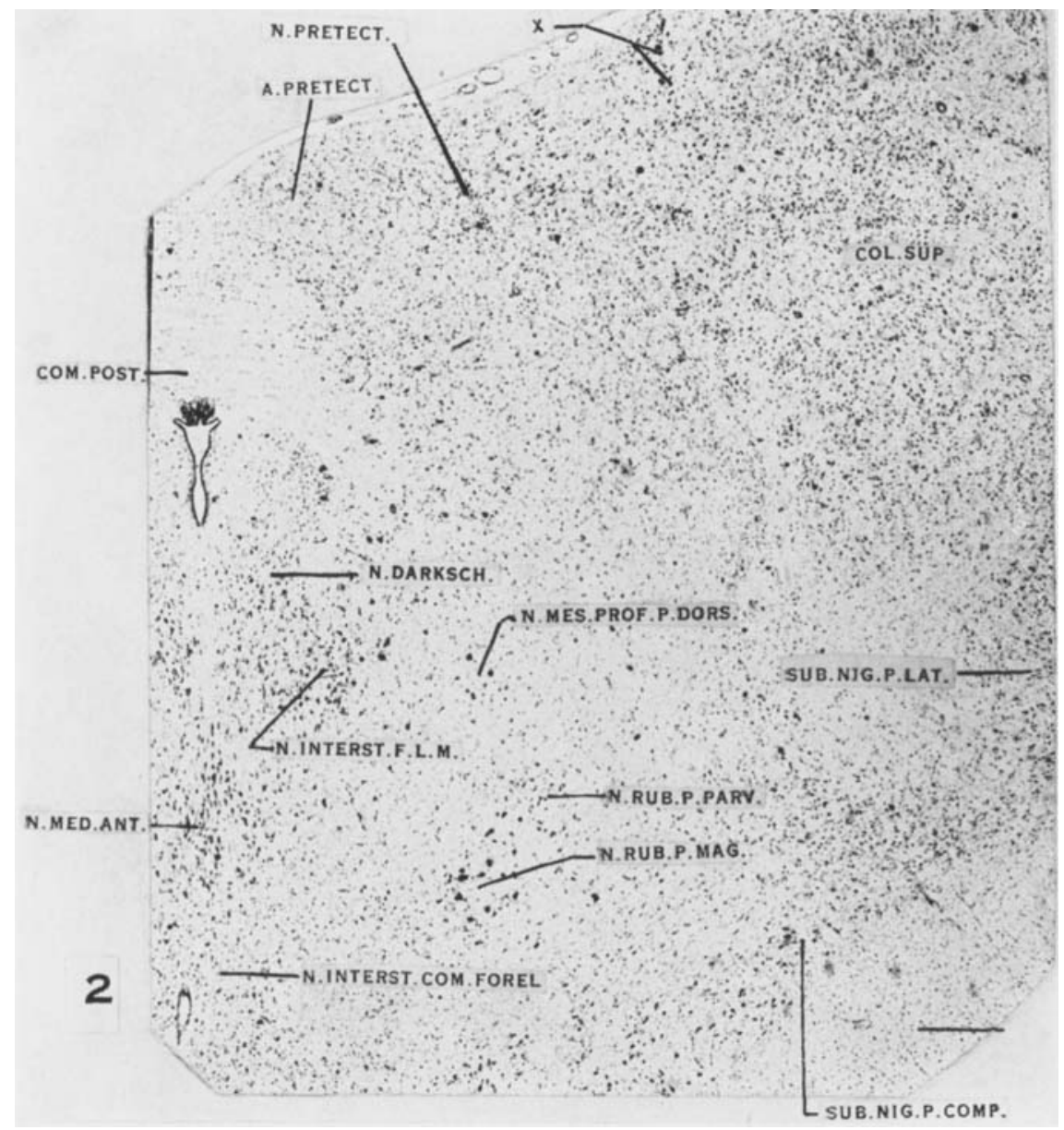

2 Plotomicrograph of a transverse section of the midbrain of the mink in a plane through the posterior commissure and the nueleus medianus anterior. At this level both parvocellular and magnocellular portions of the red nucleus are present. Toluidin blue preparation. $\times 20$. 
PLATE 3

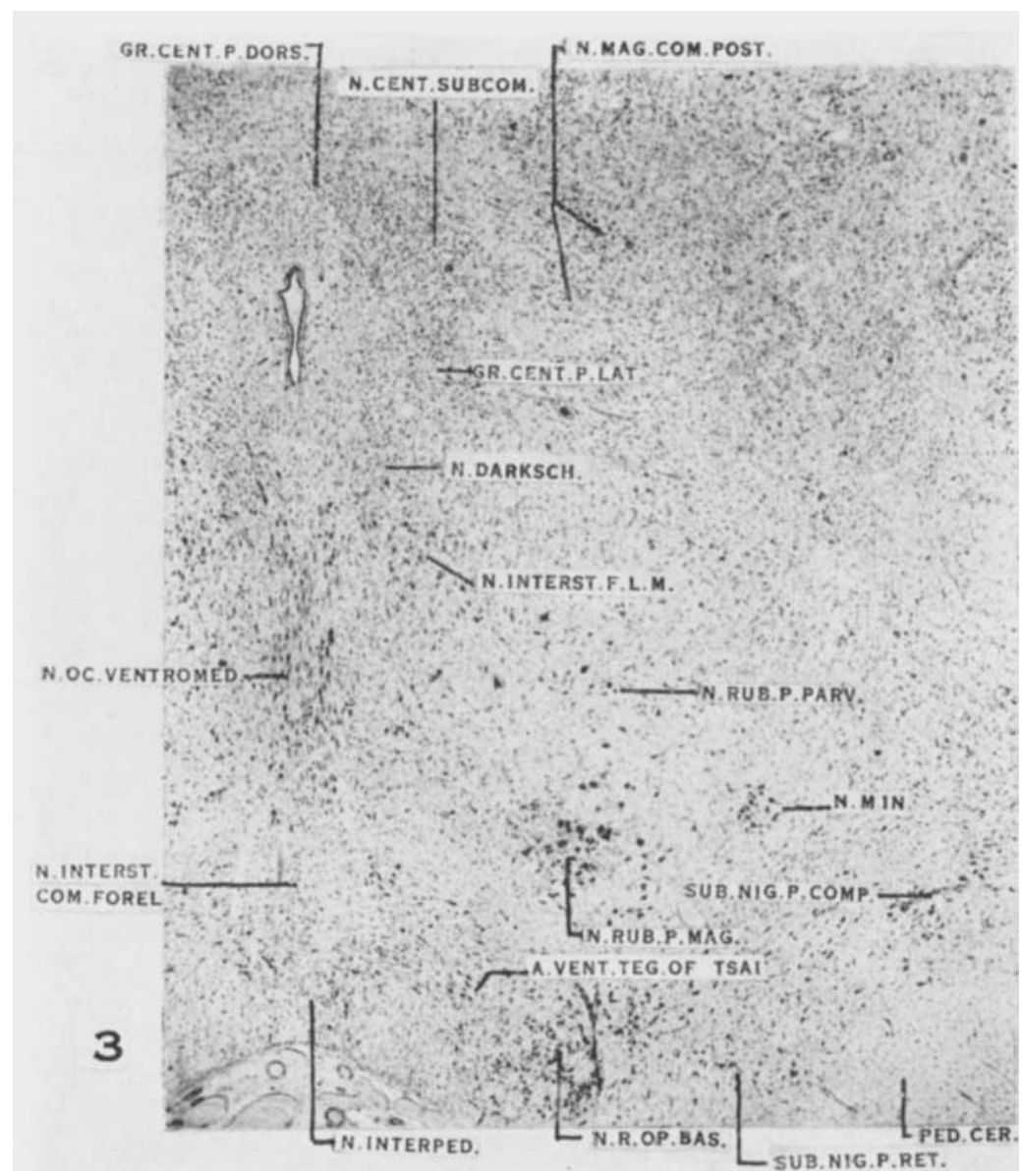

3 Photomicrograph of a transverse section of the midbrain of the mink immediately caudal to the plane of figure 2 . Toluidin blue preparation. $\times 20$. 
PLATE 4

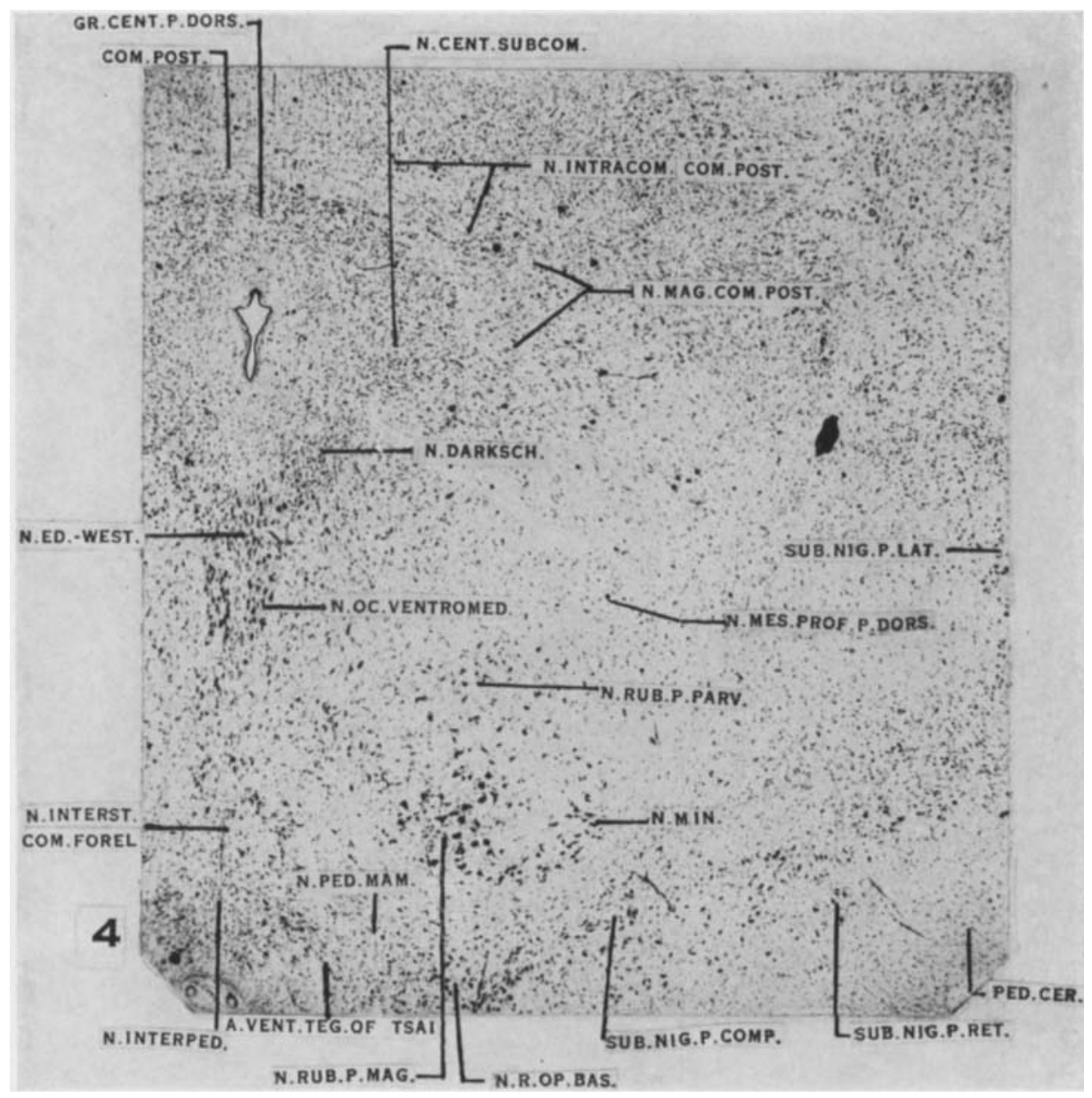

4 Photomicrograph of a section of the same series as figure 3 at a slightly more caudal level. Toluidin blue preparation. $\times 20$. 
PLATE 5

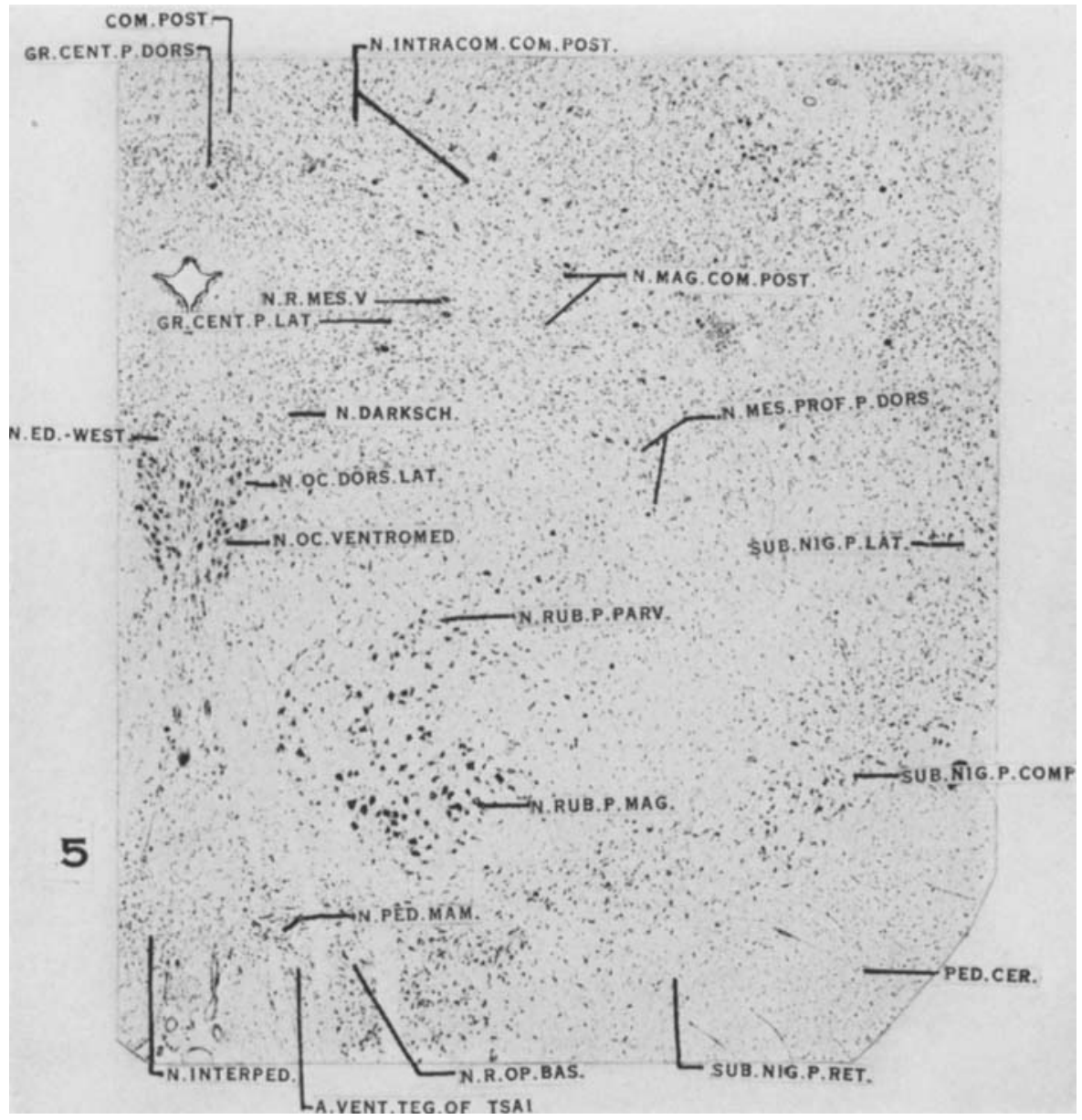

5 Photomicrograph of a section of the mink brain at the level of greatest development of the oculomotor complex. Toluidin blue preparation. $\times 20$. 
PLATE 6

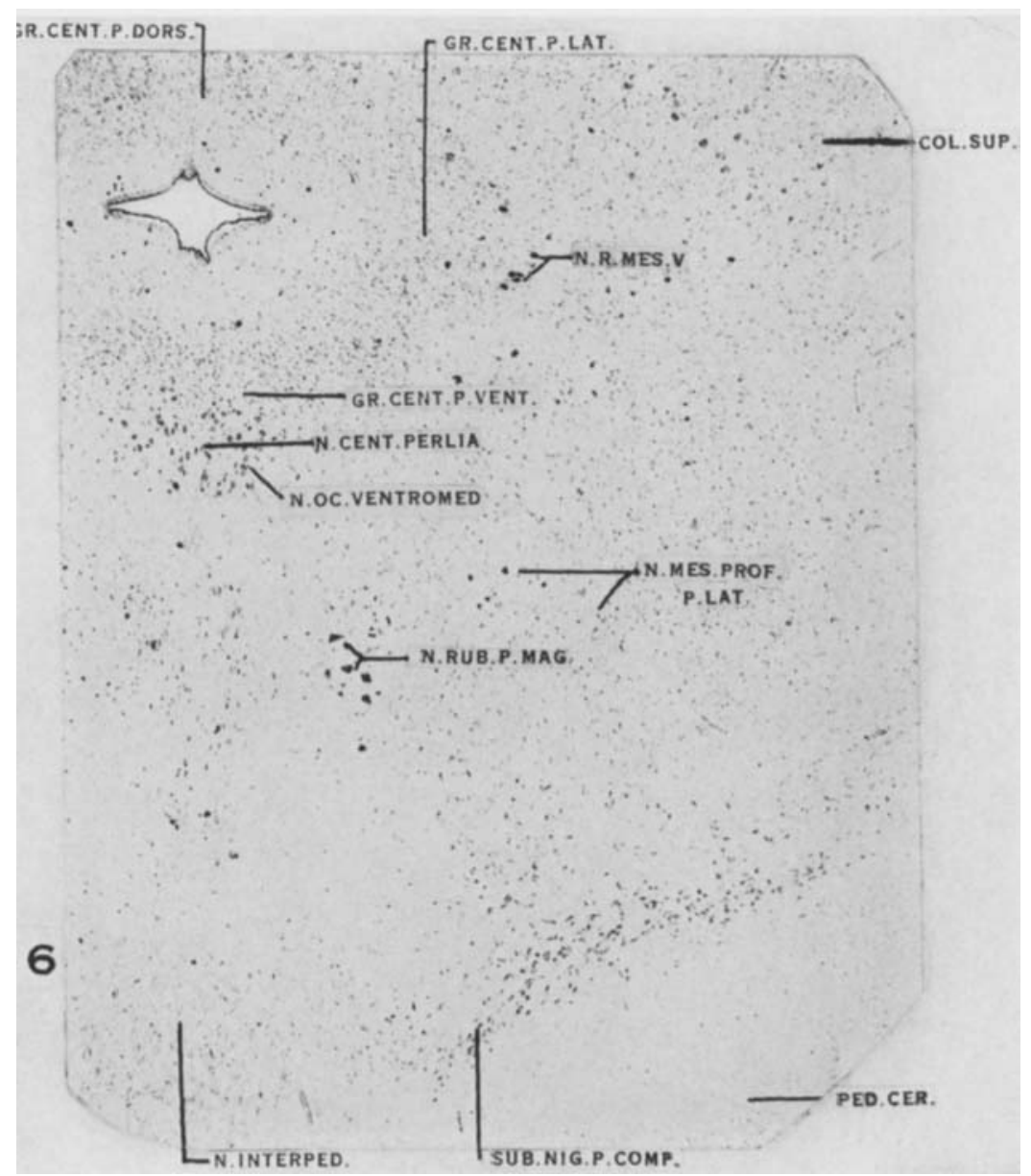

6 Photomicrograph of a section through the midbrain of the mink at the level of the eentral nueleus of Perlia. Toluidin blue preparation. $\times 20$. 


\section{PLATE 7}

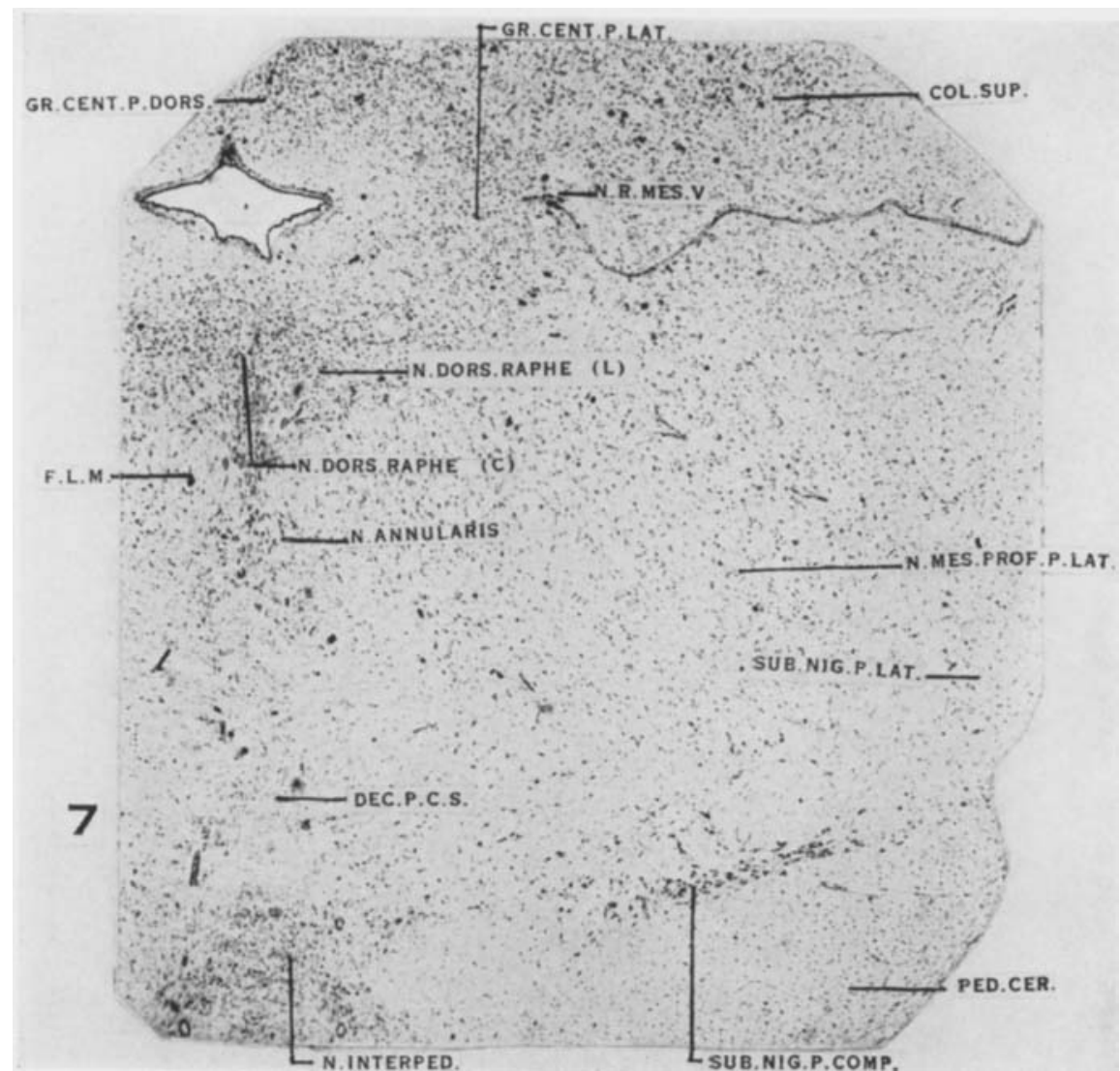

7 Photomicrograph of a section caudal to that of figure 6 showing the annular nuclens of the medial longitudinal fasciculus and the dorsal nucleus of the raphé. Toluidin blue preparation. $\times 20$. 


\section{PLATE 8}

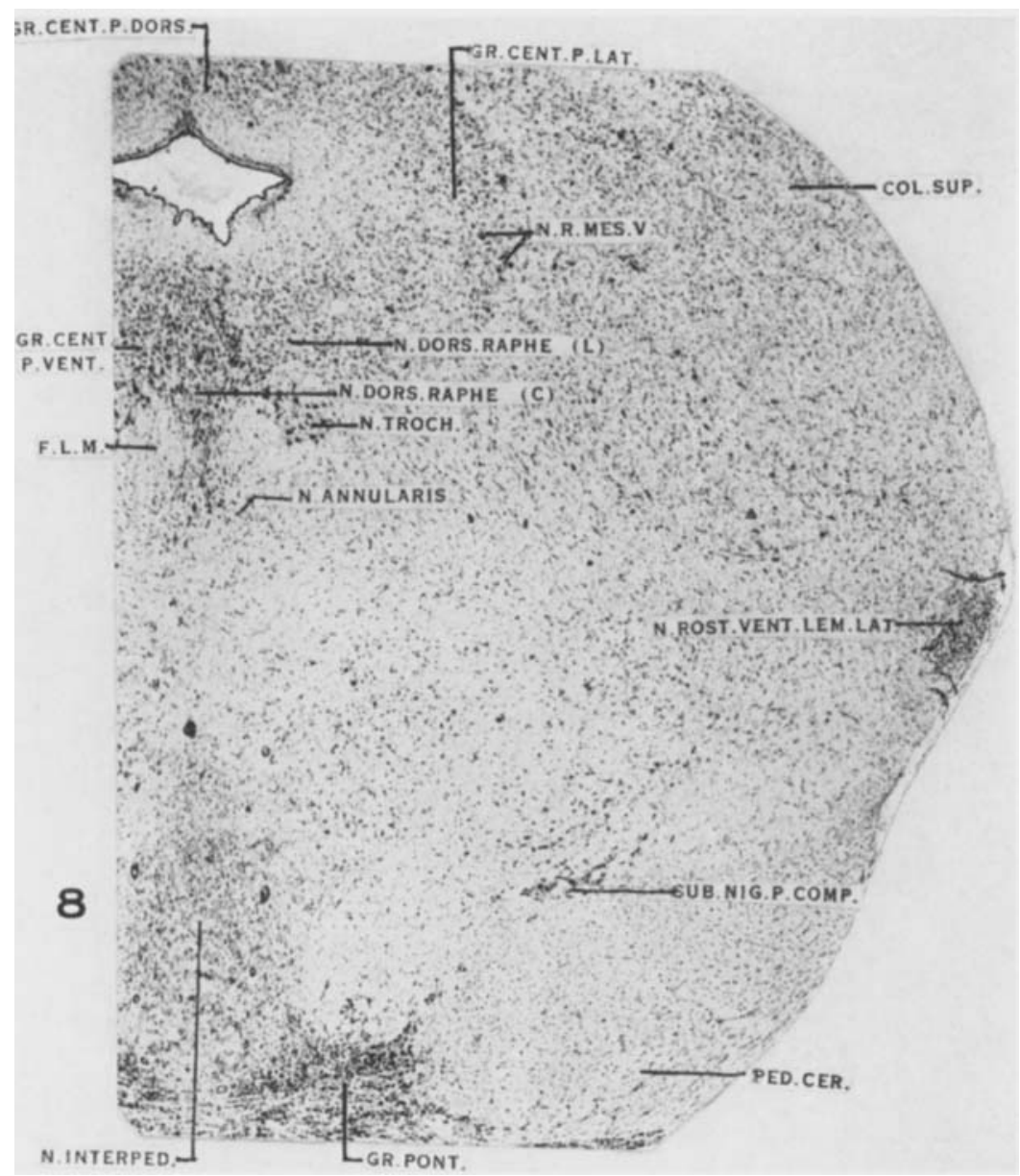

8 Photomicrograph of the mink brain at a level showing the dorsal nucleus of the raphé and the trochlear nucleus. Toluidin blue preparation. $\times 20$. 
PLATE 9

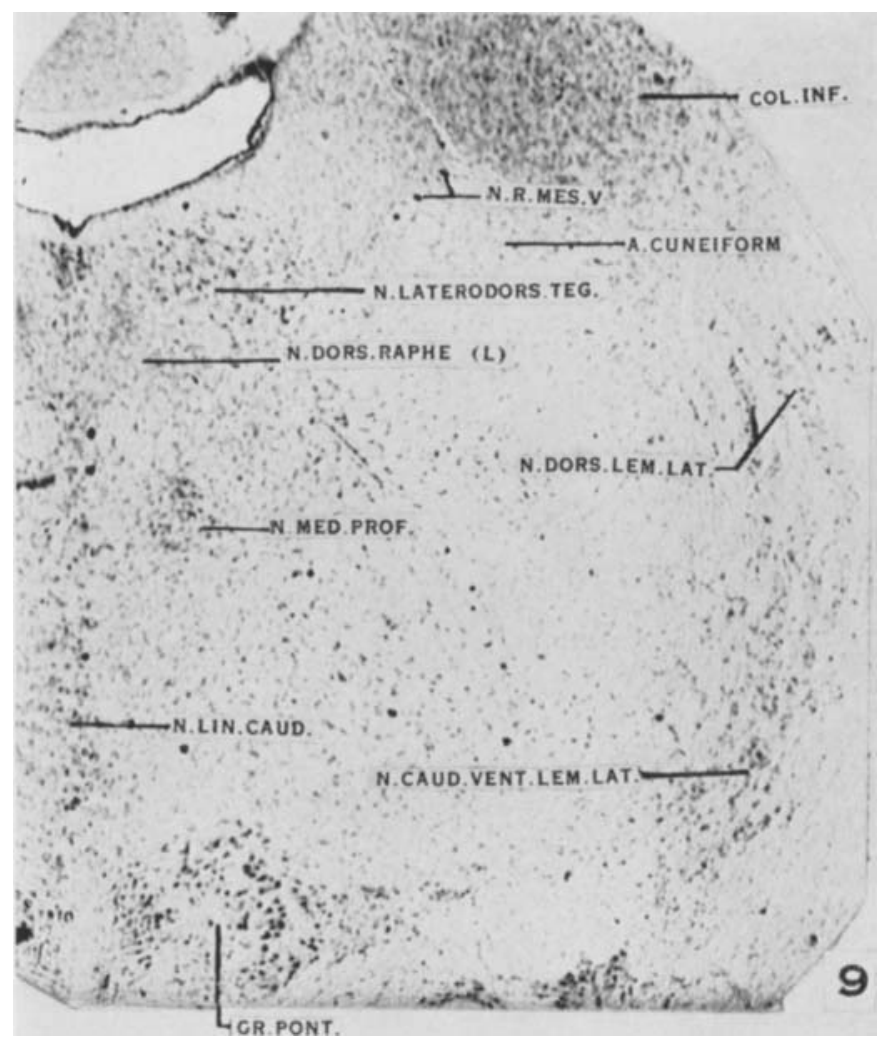

9 Pliotomicrograph of a transverse section of the mink brain through the laterodorsal tegmental nucleus. Toluidin blue preparation. $\times 20$. 


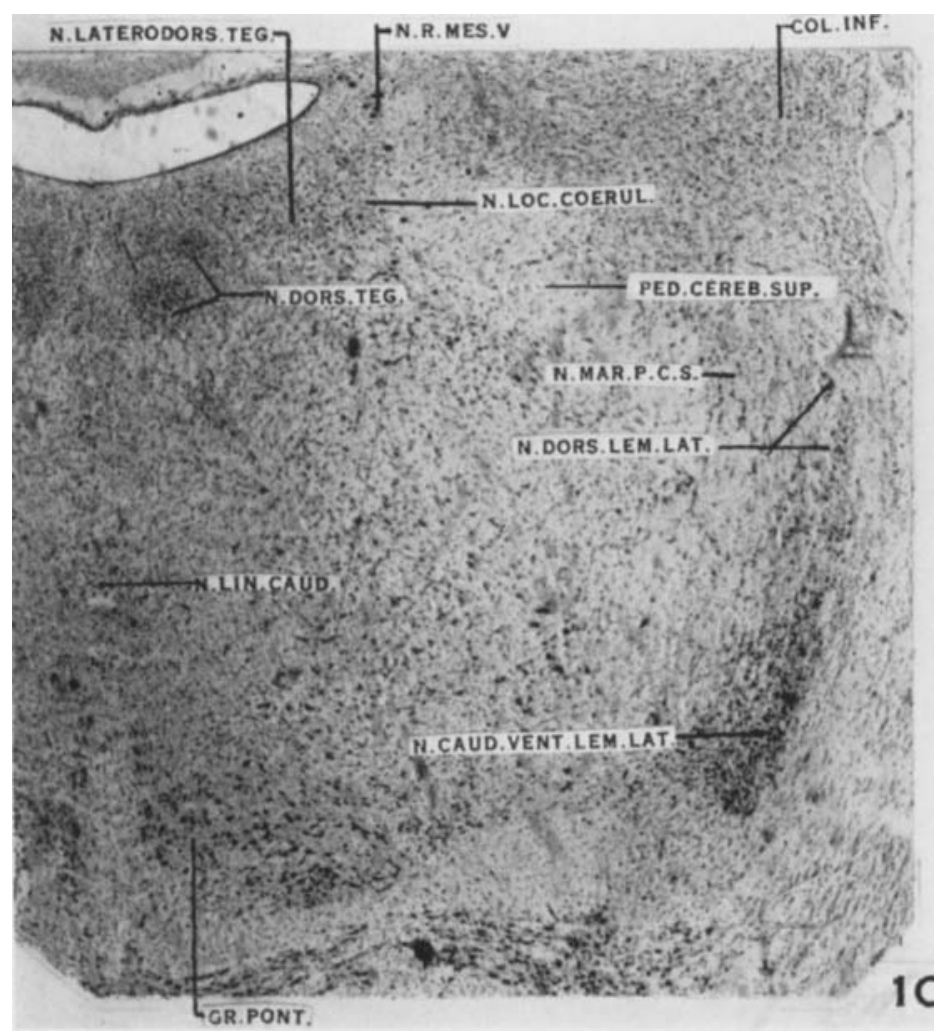

10 Photomicrograph of a section through the caudal pole of the midbrain of the mink showing the dorsal tegmental and the laterodorsal tegmental nuclei. Toluidin blue preparation. $\times 20$. 


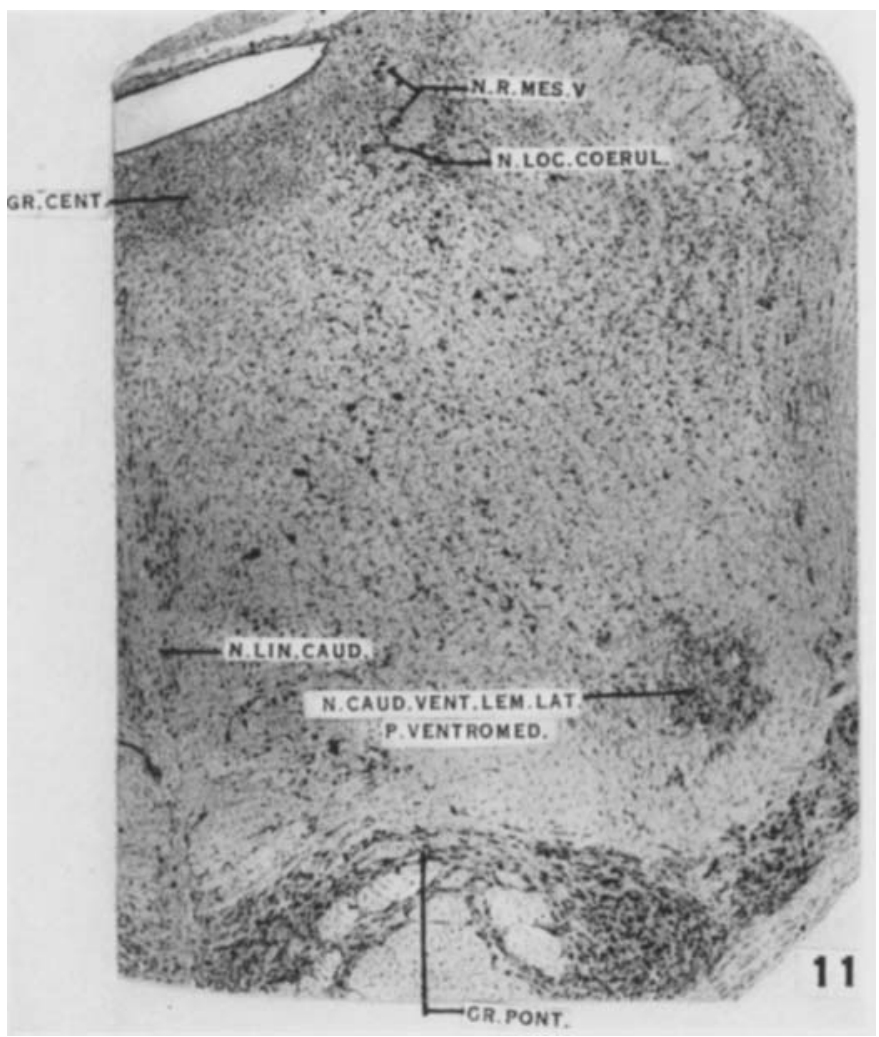

11 Photomicrograph of a section of the mink brain through the isthmus region caudal to the dorsal tegmental nucleus. It shows the intermingling of the cells of locus coeruleus and those of the nucleus of the mesencephalic root of $V$. Toluidin blue preparation. $\times 20$. 